\title{
The nature of neighborhoods: using big data to rethink the geographies of Atlanta's Neighborhood Planning Unit system
}

\author{
Forthcoming in Annals of the American Association of Geographers
}

\author{
Taylor Shelton ${ }^{\mathrm{a}}$ \\ taylor.shelton@msstate.edu \\ Ate Poorthuis ${ }^{\mathrm{b}}$ \\ ate_poorthuis@sutd.edu.sg
}

${ }^{a}$ Department of Geosciences, Mississippi State University, Mississippi State, MS 39762

${ }^{\mathrm{b}}$ Humanities, Arts and Social Sciences, Singapore University of Technology and Design, Singapore

\begin{abstract}
$\underline{\text { Abstract }}$
Neighborhoods have long held a central place in the analysis and planning of urban spaces. Despite this centrality, the exact definition of a neighborhood, as well as how and where to draw its boundaries, has remained unclear. And while these questions have generated significant academic debate, they have arguably little effect on people's everyday lives or decision-making processes. Atlanta, Georgia represents a different case, however, because of the city's system of 'neighborhood planning units' (NPU), which has shaped the city's planning and political processes since the mid1970s. But despite significant changes within the city's intra-urban geography since the 1970s, the geography of the NPU system has remained largely unchanged.

As such, this paper attempts to harness the potentials of big data to rethink the nature and geographies of Atlanta's neighborhoods. Drawing on archival documents, historic maps of the city's neighborhoods and new sources of big data, this paper explores the evolution of Atlanta's neighborhoods from the 1960s up to the present day. In particular, our analysis highlights the fundamentally fuzzy, fluid and relational nature of neighborhoods, both in the ways neighborhoods are defined by political and administrative entities and through the everyday lives of residents. Ultimately, this work calls into question the idea of the neighborhood as a natural, pre-existing, discrete and static spatial unit, and points to the utility of using new sources of data and analytical techniques for revealing this underlying relationality.
\end{abstract}

\section{$\underline{\text { Keywords }}$}

big data, neighborhoods, regionalization, socio-spatial theory, urban geography 


\section{Introduction}

As cities become ever more central to our understandings of the contemporary human condition, and attempts to plan for it, so too do cities become subject to ever more diverse forms of scrutiny. With the advent of emerging sources of so-called 'big data', it has become possible to analyze a wider array of urban social and spatial processes than is possible with conventional sources of census data alone, and at finer spatial and temporal scales than would otherwise be possible. Whether in the form of geotagged social media data, smart cards used for accessing public transit, or 311 systems for cataloguing municipal maintenance requests, these new sources of data potentially allow for a richer understanding of urban life that complements longer-standing ways of analyzing and understanding cities through data.

These new sources of data are typically employed, however, in a way that produces, more than just reflecting, urban space and socio-spatial relations. That is, even though these new sources of big data allow for a greater degree of flexibility in their spatial epistemologies, analyses of this data still often default to using the received spatial categories of administrative or statistical geographies as units of analysis. Because these more conventional geographic delineations - such as that of the neighborhood, with the census tract as a rough proxy - are both familiar to us, as well as being the scale at which other kinds of social data gets aggregated and made public, these geographies continue to have a powerful hold on the way we come to know cities.

But this process isn't new. Indeed, as one practitioner of the emerging field of 'urban data science' remarked at a recent workshop, "the history of urban science is the history of neighborhoods". That is, geographic constructs such as the neighborhood have long had a structuring effect on the way social scientists have thought about, and ultimately intervened in, urban processes. From the early 
Chicago School of urban sociology and its focus on 'natural areas' of the city to the development of factorial ecologies as a refinement of these approaches, all the way up to genesis of the 'neighborhood effects' school of research, the somewhat fuzzy ways that neighborhoods or other sub-urban geographies have been defined have played an important constraining role in our study of urban space. Ultimately, these different successive strands of research have served to reify the urban neighborhood as a kind of discrete spatial unit with distinctive characteristics and a determinative effect on the social life of those within it. Rather than seeing neighborhoods as being produced through social relationships and processes, this work falls into the trap of 'spatial fetishism', of seeing inherently spatial processes as preceding, and ultimately determining, the social itself (Soja 1980).

While some of these established paradigms have turned to big data as a way of supplementing or strengthening their existing research programs, our work isn't about designing more efficient or accurate metrics for cities and urban neighborhoods using big data, or developing ostensibly 'universal' laws by which cities operate (Bettencourt and West 2010). Instead, this paper attempts to harness the potentials of big data to rethink the nature of these spaces in the first instance, to call into question the conventional ways that we've partitioned urban space for the purposes of producing knowledge about it and governing it. While GIS and quantitative geography have long been critiqued for their singular reliance on a Cartesian understanding of space like the one that underpins dominant understandings of neighborhood (Sheppard 1995; O’Sullivan et al 2018), this paper demonstrates that big data offers meaningful potential for bringing together GIS and quantitative methods with relational understandings of space and place that have dominated human geography over the last two decades or more. 
Using an extensive database of geotagged tweets, the rest of this paper sets out to reimagine and redraw neighborhood boundaries in Atlanta, Georgia based on the everyday mobilities of urban residents. Because Atlanta has enshrined its definitions of neighborhoods into the city's planning process since the early 1970s via its 'Neighborhood Planning Unit' (NPU) system, it provides a compelling case for understanding the dialectic of stability and change in neighborhood boundaries over time, and demonstrating how emerging sources of big data can provide a contemporary perspective on how these spatial delineations do or do not accord with the lived geographies of urban residents and their everyday activities. Using Atlanta as a test case, we hope to demonstrate that big data can help to construct alternatives to conventional socio-spatial imaginaries that promote the stigmatization of certain neighborhoods, as well as to demonstrate the fundamental interconnection of places that are often assumed to be wholly separate and apart from one another.

First, the paper reviews the way neighborhoods have been conceptualized within different schools of thought in geography and other relevant social sciences, emphasizing the potential for a more relational understanding of neighborhoods to be operationalized later in the paper. Second, the paper provides a brief history and overview of Atlanta's NPU system. Finally, the paper turns to using geotagged tweets as the basis for a redrawing of Atlanta's neighborhoods and NPUs. By combining this big data-based analysis with an analysis of historic maps of Atlanta's neighborhoods and their evolution, this section seeks to explore the tensions between a static, Cartesian understanding of urban neighborhoods and a more fluid, processual, and relational understanding, and the potential for these new sources of data to advance such a theoretical project of rethinking the spatial ontology and epistemology of the neighborhood. This redrawing exercise is not, however, meant to argue that neighborhoods don't matter. Indeed, this analysis is meant to demonstrate that neighborhoods very much matter, but that in many cases, our received understandings of what 
constitutes a given neighborhood are incredibly partial and that alternative understandings of neighborhood may matter more in some contexts.

\section{Rethinking the Neighborhood}

Even after a century of focus, the concept of neighborhood remains one with an imprecise definition. While definitively operating at a sub-metropolitan level, there is no consensus about what precisely it is that defines a neighborhood. In practice, such definitions can be even more elusive, with neighbors - or even family members - having different conceptions of where one's neighborhood boundaries lie. This fuzziness is so pervasive that Galster (2001) likens the debate about the nature of neighborhoods to the legal understanding of pornography: "a term that is hard to define precisely, but everyone knows it when they see it" (2111). The rest of this section reviews some of the prominent ways that neighborhoods have been conceptualized amongst geographers and other spatially-oriented social scientists throughout the last century, how these variations definitions of neighborhood are operationalized in practice, and the role of new data sources and mapping technologies in enabling new approaches to understanding neighborhoods.

\section{A. Theorizing the Neighborhood}

Most commonly since its emergence as a key concept with the social science literature, the neighborhood has been understood as a kind of spatial container. Beginning with the Chicago School of urban sociology, neighborhoods were seen as 'moral regions' with distinct characteristics from other such regions, as a kind of fundamental organizing unit for urban space (Park 1915). While this view most often seen in Burgess' (1923) concentric zone model of the city, it's just as evident in the Chicago School's mobilization of the biological metaphors of neighborhood 'ecologies' and 'natural regions' (Zorbaugh 1926; Park 1936). 
This understanding of neighborhoods came to dominate the urban social sciences throughout the $20^{\text {th }}$ century, leading to a consolidation of what Madden (2014) calls 'the Westphalian neighborhood imaginary'. For Madden, this view of the urban space "portrays the city as fully divided among different neighborhoods pictured as non-overlapping and of clear outline, almost as sovereign republics. Just as the vision of the world chopped into sharply demarcated, bounded nation-state units reflects (and produces) a distorting, ideological image, so too does the vision of the city chopped into sharply demarcated, bounded neighborhood units” (Madden 2014: 473). But, crucially, he argues that this naturalistic way of understanding urban space ultimately tends to be ahistorical, functionalist and depoliticizing, failing to recognize the multiple ways that the question of what and where neighborhoods are is an intensely political question that transcends the ostensible fixity of the neighborhood itself.

In response to this bounded, mutually exclusive conception of neighborhoods has been a growing chorus of work focused on articulating a broadly relational understanding of neighborhoods. Influenced in large part by Massey's (1991) invocation of a 'global sense of place', this relational perspective seeks to put the ostensibly bounded, self-contained neighborhood within a broader set of social and spatial relations, instead seeing neighborhoods as contingent, overlapping and even spatially discontinuous, only ever a temporary result of particular social and spatial flows and trajectories that might be reassembled in different ways moving forward (cf. Pierce et al 2011). While Massey undoubtedly plays an important part in providing the language for such a relational view, similar perspectives were circulating even earlier. For instance, Hunter (1979) offers a kind of protorelational view of the neighborhood when he argues that "To try to understand the neighborhood solely by focusing on its internal structure and dynamics is to end up with carefully documented descriptions, but a persistent failure to grasp the causal explanations of the processes that create the 
variety of neighborhood forms and constrain the conduct of neighborhood life. If one does not view the neighborhood within its context, in short, one ends up with description, not explanation" (269). That is, our understanding of the neighborhood requires that we actually go beyond the neighborhood itself in order to understand the trans-local connections that constitute the neighborhood as such.

\section{$\underline{\text { B. Delineating Neighborhoods }}$}

While the question of what the essential nature of a neighborhood is has persisted, this question has often been turned into a perhaps even thornier question of how one might operationalize these different conceptions. Given the variety of characteristics that are accepted - albeit to varying degrees - as constitutive of a neighborhood, how do we then identify these neighborhoods in particular concrete cases; how do we distinguish one neighborhood in a given place from its neighbor(s)?

Arguably the most common way of operationalizing neighborhood geographies is through official statistical geographies, such as the Census tract in the United States. Because these units are the smallest scale at which most social data is made publicly available, any research on neighborhoods that relies on official statistics tends to be limited to these predefined areas. The reality of these spatial units is that they have no necessary connection to the lived geographies of the neighborhoods themselves, and such neighborhood boundaries often encompass multiple tracts. Even in those places where neighborhoods might be administratively-defined, the administrative and statistical geographies need not be in accordance with one another. As Sperling (2012) has argued:

"The singular and strict use of block groups, census tracts, or ZIP Codes as proxies for neighborhood, however, are often inappropriate and can result in flawed findings, poor public policy decisions, and even situations in which families or businesses are disqualified from place-based government programs. Perceptions of 
neighborhoods are social constructs and context dependent. Yet social science literature is replete with an unquestioning use of these geographies to measure neighborhood effects, despite evidence that the use of alternative spatial scales and techniques can deliver very different results." (219)

That is, the fact that statistical geographies operate in a recursive, mutually reinforcing relationship with the Westphalian understanding of neighborhoods as bounded containers, while also being divorced from the actual conceptions of neighborhoods held by residents, can present substantive conceptual and methodological problems for researchers. As Flowerdew et al (2008) have shown, using different definitions of neighborhoods at non-conventional scales can change whether or not a so-called 'neighborhood effect' is observable. Or, as Jones and Pebley (2014) demonstrate, failing to account for people's everyday mobilities and activity spaces by looking only at one's immediate residential context, provides an impoverished view of both the spatiality of the neighborhood and how spatial context influences a variety of social outcomes. Furthermore, acknowledging that neighborhoods are not only modifiable in their spatial size, but also over time, can present further difficulties to creating consistent and reproducible neighborhood geographies (Sperling 2012; Taylor 2012; Kwan 2018).

\section{Histories of Regionalization}

The search for this kind of ostensibly objective methodology for delineating places from one another can find lineages in the longer history of regionalization methods within geography. While regionalization isn't entirely unique to geographic research - indeed, in the abstract, all it means is the classification and categorization of geographic territories - the specific methods and approaches have very much been tied to the discipline of geography. In particular, regionalization approaches emerged out of geography's so-called 'quantitative revolution' in the 1950s and 60s, not only as one potential realm in which computational analysis could be useful, but also as a particular area of study 
that would help make geography a more 'scientific' discipline (cf. Schaefer 1953; Bunge 1966; Harvey 1969).

This question of delineating regions or sub-metropolitan neighborhoods using quantitative and computational methods has nonetheless occupied geographers and other spatial social scientists for some time. Some of the earliest research on regionalization focused on the identification of so-called 'formal regions', or places that are uniform and homogeneous, grouped together based on their similarity according to a series of given variables. Consolidated under the banner of 'social area analysis' (Shevky and Bell 1955) and later 'factorial ecology', this line of research is often associated with the quantitative revolution due to the work of Brian Berry (Berry 1961, 1971; Berry and Kasarda 1977). That being said, the search for such regions is in many ways a synthesis of the discipline's quantitative-nomothetic and Hartshornian regionalist-idiographic traditions, seeking to both find consistency in these landscapes while also being limited to a largely descriptive analysis of regions, rather than an analysis of the underlying processes that produce these regions as such.

While the 'formal' definition of a region approximates the dominant vision of neighborhoods, of greater interest to the present research is the application of regionalization methods to the search for 'functional regions'. Functional regions are those areas defined by the substantive interactions or linkages between different locations. That is, functional regions group together places that interact more with each other than with other locations outside of the region. While often applied to the more conventional sub-national understanding of the region prominent within geography at the time (Nystuen and Dacey 1961; Garrison and Marble 1964), some studies of functional regions were focused at the urban scale, delineating sub-metropolitan neighborhoods based on transportation or telecommunications networks (Hemmens 1966; Goddard 1970). Hemmens' (1966) dissertation on 
Buffalo is particularly interesting in that its regionalization output, based on travel data, operationalize a rudimentary understanding of relational space. Whereas most regionalization efforts hold the assumption that regions must be contiguous, Hemmens' work identifies spatially discontiguous neighborhoods, acknowledging that the functional connections between places aren't necessarily dependent upon immediate spatial proximity or contiguity, an insight we attempt to extend in our analysis below.

It is important to note, however, that for all of the enthusiasm around and applications of regionalization methods, there was some recognition at the time, even amongst advocates, that these methods were incredibly partial (cf. Grigg 1965; Lankford 1969). This acknowledgment of the fuzziness and subjectivity in regionalization processes is applicable not only to the epistemological and ontological positions of the researcher undertaking regionalization research - i.e., that any regionalization output is shaped by the concerns of the analyst producing it - but also of the spatiality of the regions themselves. As Gale (1976) suggests, the failure of regionalization algorithms to acknowledge the existence of anything beyond non-fuzzy boundaries and constrained single membership means that these algorithms also fail to reflect the underlying ontology of the region as we know it. Together, these statements point towards what we might call an early post-positivist approach to regionalization that is not in search of an incontrovertible truth about regions or neighborhoods, but rather employs regionalization as a useful, and at times necessary, heuristic device for generalizing spatial patterns. In the absence of identifying an inherently optimal classification of regions or neighborhoods, this approach suggests that we should seek out many different classifications simultaneously, allowing the particular purpose, context and rationale for study to identify the most appropriate result, but always with an eye towards using these methods of ways of thinking about space in new ways. 


\section{New Forms of Data-Driven Neighborhood Delineation}

More recently, however, a number of projects have attempted to take advantage of crowdsourced geographic data precisely in order to capture the otherwise non-codified geographies of neighborhoods. One notable example is the Bostonography project (Woodruff 2013), which is based on crowdsourced inputs of users' mental maps. While initially structured around drawing the boundaries of established neighborhoods, the project has since shifted to allowing users much greater leeway in identifying points or areas of interest. The resulting maps demonstrate the fundamental fuzziness in these definitions, simultaneously highlighting those areas where there is (near) consensus on the definition of a given neighborhood, as well as those places where there is significant contention about what a given area is called and where its boundaries are.

More commonly, researchers have taken to the wealth of user-generated geographic data created through social media in order to produce similarly fuzzy understandings of neighborhood boundaries. The Neighborhood Project (Chisholm and Cohen n.d) mines Craigslist housing advertisements for the names of city neighborhoods, and then maps how these different neighborhood designations are used in different places, often in overlapping and spatially discontiguous ways. Similarly, Cranshaw et al's (2012) Livehoods project uses Foursquare check-ins as a way of demonstrating the social connections between different kinds of establishments, while Arribas-Bel's (2015) 'spoken postcodes’ compares Amsterdam’s long-established postcode neighborhood geographies to the ways that Twitter users inhabit and move through different parts of the city. Shelton et al's (2015) examination of the ' 9 th Street Divide' in Louisville also uses geotagged tweets to show that a predominantly poor and African-American neighborhood conventionally conceived of as separate and isolated from the rest of the city is actually quite 
meaningfully integrated into the rest of the city, overlapping with more conventionally affluent and white spaces.

One thing that each of these examples of neighborhood redrawing have in common is that their reimagining of neighborhood boundaries has little impact on the way people live their lives in these places. As Crampton (2006) has argued, “[d]rawing lines on maps can seem an arid academic exercise" (747). While many of the aforementioned works have demonstrated that neighborhoods remain important for the way they convey a sense of place or allow residents to stake claims on particular places, the precise structure of these neighborhoods - whether a boundary between two neighborhoods is drawn straight down the middle of a street or zigs and zags to capture some places while intentionally excluding others - doesn't really affect people's everyday lives or decision-making processes. Atlanta, however, is different because of the way that popular understandings of neighborhood boundaries became formalized and aggregated together into neighborhood planning units, which play an influential, if disputed and sometimes problematic, role in the city's planning process. That is, in Atlanta, the way neighborhoods have been delineated from one another - a process that was sometimes arbitrary and sometimes a tool of racism and social control - has important ramifications for who gets to have input into particular urban policy and planning decisions.

\section{A Brief History of Atlanta's Neighborhood Planning Unit System}

Despite being generally heralded within planning circles as a model for integrating neighborhoodbased citizen participation into planning processes, Atlanta's NPU system has scarcely been subjected to critical scrutiny since its inauguration over fifty years ago. Indeed, where the NPU system appears in the scholarly literature, it is often according to a common origin story that 
describes how the NPU system was created in 1974 as one of newly-elected Mayor Maynard Jackson's first major initiatives, so as to provide a more direct means of representation and participation for black citizens in Atlanta as the city entered a new era of black political power and representation (cf. City of Atlanta n.d.).

But this version of the NPU's origin story is whiggish, at best, and ultimately disguises the political contestations and negotiations that gave rise to the contemporary NPU system. While Maynard Jackson's election as Atlanta's first black mayor in 1973 did indeed owe partially to his harnessing of the nascent neighborhood movements occurring around the city in the preceding years (Parko 1975), the NPU system was not simply Jackson's brainchild, nor was it simply proposed and implemented immediately upon Jackson's taking office. It was instead an adaptation of an idea that been floating around Atlanta's planning and policymaking circles for at least a few years, and one that was certainly not well-received by all involved parties, especially on the city council, resulting in extensive negotiations and contestations over its formulation and implementation.

\section{A. Contesting the Neighborhood Planning Unit Concept}

The City of Atlanta's 1967 “Social Report on Neighborhood Analysis”, published a year before Jackson had even formally entered the political arena, points towards a program of neighborhoodbased citizen participation in planning much like the one eventually enshrined in the NPU system. While the report ultimately defers on the creation of any concrete mechanisms for ensuring such participation in favor of a more ad hoc participation process, it does represent something of a forerunner to the eventual NPU system. The report itself was based on a division of the city "into 23 areas that are fairly homogeneous...organized by census tracts... [and thus] only approximat[ing]

the traditional boundaries of neighborhoods or combinations of neighborhoods" (City of Atlanta 
1967: B2-B4). Several years later in August of 1973, during the mayoral primary that pitted Jackson against incumbent Sam Massell and former congressman Charles Weltner, Weltner proposed a similar notion of devolving power to neighborhood groups through neighborhood city halls and citizen's advisory councils (Linthicum 1973). While few other details are available about either Weltner's vision or that of the 1967 report, it is at least evident that the idea of neighborhood-based planning had been on the agenda for some time before its eventual adoption under Jackson's watch with the 1974 Neighborhood Planning Ordinance.

While the issue of when and by whom the NPU idea originated may be somewhat pedantic, it is perhaps most important to recognize that throughout the genesis of the NPU system in the years after the passage of the neighborhood planning ordinance, the idea of 'neighborhood planning units' as such was incredibly contentious. Most notably, a number of sitting city councilmembers saw the addition of a new kind of supplementary political geography into the city's planning apparatus - one which, by design, wouldn't accord with the existing city council district boundaries - as a threat to their political power. Proponents of the neighborhood planning program accused their fellow councilmembers of putting a desire for "political fiefdoms" ahead of the city's need for "rational planning units” (Merriner 1975a).

In the end, the fight over the NPU system waged for well over a year, from the spring of 1974 at least through the spring of 1975, though it remains unclear based on archival evidence when precisely the council came to an agreement about the matter. The contention around the NPU system was so great that within just a couple of years of its implementation, the program was already under significant attack within the city, both from its original detractors and from proponents of the system who felt like it wasn't living up to its potential (Martin and Holmes 1978; Russakoff 1978; 
Saporta 1982; Anderson 1985; Foskett 1992; Wheatley and Isaf 2015). This fight suggests, however, the great importance of geography to the questions of planning and citizen participation that Atlanta was grappling with in the 1970s. While neighborhoods are often used as a kind of default scale for grouping and understanding sub-urban areas, settling on neighborhoods as the geography at which Atlanta's citizen participation would be organized was anything but a straightforward, rational process. Indeed, the creation of an incongruent system of administrative geographies through the addition of the NPU system was meant to not only reshape and redraw the lines on the map, but also the structures of power within the city itself.

\section{B. Defining Atlanta's Neighborhoods and NPUs}

While the geographies of Atlanta's citizen participation were indeed contentious, the neighborhood was ultimately accepted as the scale at which such a process would be organized. But this leaves open the important question of how the city actually decided what constituted a neighborhood, how boundaries were drawn between neighborhoods, and how constituent neighborhoods were then aggregated into the system of NPUs.

The official definitions for a neighborhood and NPU were approved by the city council on April 2, 1975, though the council declined to approve the official neighborhood boundaries at that time because a revised map was not available (Merriner 1975b). The city defined a neighborhood as "a geographic area either with distinguishing characteristics or boundaries in which the residents have a sense of identity and a commonality of perceived interest, or both" and an NPU as "a geographic area composed of one or more contiguous (connecting) neighborhoods, which have been defined by the Department of Budget and Planning and approved by the City Council for the purpose of developing neighborhood plans", though these definitions had been in informal use in earlier 
planning documents produced by the city (cf. City of Atlanta 1974: 27). Though the official definition of an NPU left open the possibility of an NPU comprised of only a single constituent neighborhood, no NPU actually holds this designation. According to then-Planning Commissioner Leon Eplan, who had arguably the most formative role in the creation of the NPU system (Campbell 1996), the rationale and process for grouping neighborhoods into NPUs was the following:

“...the Bureau of Planning prepared a city-wide map showing 177 so-called 'neighborhoods' in Atlanta. These areas were predominantly residential clusters, or sometimes small commercial nodes, with clearly defined boundaries and names. Some were quite large in size, while others were very small... With only a limited planning staff for the planning and participation program, and with so many neighborhoods to service, it became necessary to bundle the neighborhoods into larger units. Neighborhoods were placed together when they were physically close and appeared to have similar interests or characteristics... Identifying the appropriate name for each neighborhood was deemed essential. Establishing and maintaining neighborhood identity was central to the NPU process, to ensure that residents would identify with their communities and derive a sense of place and pride from living there" (Eplan 2014: 99)

That is, Eplan frames the necessity of grouping neighborhoods into NPUs as one based at least partially on resource constraints within city government, but also framed within a notion of creating coherent neighborhood communities that could be grouped together with adjacent neighborhoods of similar character while also remaining distinct.

These disagreements, while perhaps minor, point toward the inherent fuzziness when discussing the definition of neighborhoods, whether in a more general sense or regarding the NPU system in particular. Not only are neighborhoods subjective - what constitutes a neighborhood for one person might be different than their neighbor or a person who lives across town (Coulton et al 2001) - but they are also subject to considerable change over time. Whether due to demographic shifts, changes in social networks or social standing, political institutions or new developments in the built environment, individual perceptions of neighborhood surely evolve over time. It's important to note 
that despite the stated attempts at constructing coherent neighborhoods and groupings thereof, early official documents from the city on the NPU system recognized precisely the fact that neighborhoods aren't the bounded, coherent and stable entities they're often assumed to be.

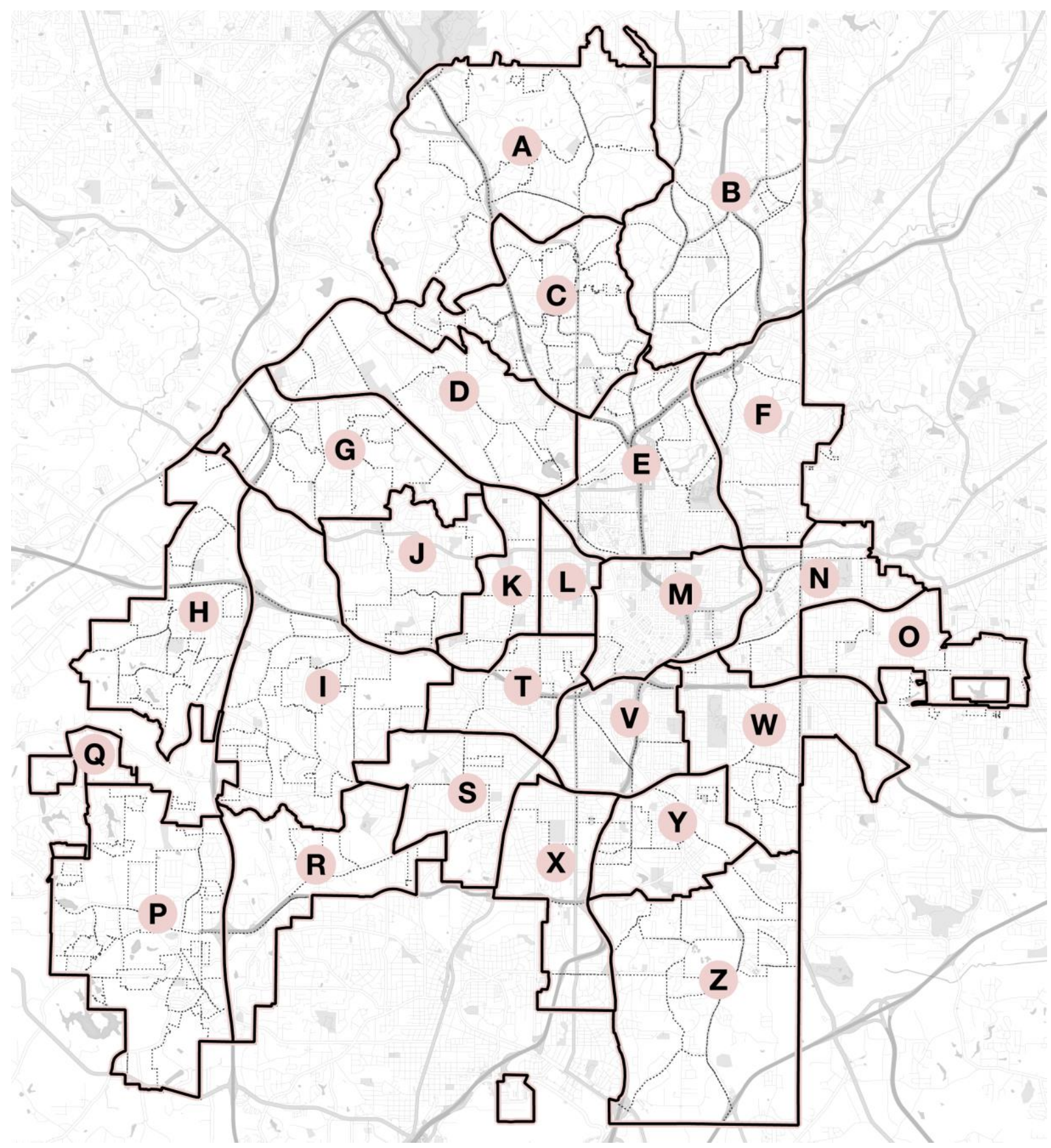

Figure 1: Atlanta's Neighborhood Planning Units (NPUs) 
One of the city's key tools in promoting the nascent plans for neighborhood planning after the adoption of the new city charter were a pair of booklets entitled "How to Do Neighborhood Planning" and "The Value of Neighborhood Planning". The latter argues at one point that "Each of Atlanta's neighborhoods is different from the others, but one element is common to them all. It is change - continuous change" (City of Atlanta 1973: 5). Indeed, as the analysis below demonstrates, archival maps of Atlanta neighborhoods used in various planning documents in the 1960s and 1970s allow one to see this continuous change made manifest in the way the city government represented these neighborhoods (see Figure 2). Even further, nearly two decades after the implementation of the NPU system, the city undertook an update of its official records of neighborhoods and their boundaries in order to reflect this dynamism (Hiskey 1991; Cordell 1992). And yet, in spite of this fact, the boundaries of the NPUs themselves have seen only very minor adjustments since their inception, with the exception of those stimulated by land annexations at the city's fringe, which resulted in the creation of NPU-Q in the city's southwest in the mid-2000s. Indeed, those adjustments to neighborhood boundaries that took place in the 1990 s were limited to changing such boundaries within each NPU, in effect ensuring that the stability of the aggregate NPU boundaries wouldn't be disrupted by such an exercise. This fact runs counter to an argument made later in the "The Value of Neighborhood Planning" booklet, that "Planning is not a once-and-done process. A plan must be kept current, reflecting circumstances which could not have been anticipated when the original Plan was prepared" (City of Atlanta 1973: 19). Given that the city has recognized on multiple occasions the need for these boundaries to be reconsidered, our contention is that perhaps the idea of planning as anything but "a once-and-done process" ought to be applied to the geographies of planning as well, in this case the geography of the NPUs. 


\section{Remapping Atlanta's Neighborhoods Using Big Data}

In this section, we take up this task of mapping continuity and change in Atlanta's neighborhood geographies, using both historical maps of the city's neighborhoods and an extensive database of geotagged tweeting activity within the city over several years. Rather than soliciting the direct contributions of residents' mental maps as in Coulton et al (2001) or Campbell et al (2009), this research uses the aggregate, everyday mobility patterns of Twitter users in the city of Atlanta as a proxy for their 'lived' neighborhoods. That is, in our redrawing of these boundaries, we are searching for the functional neighborhoods as defined by people's movements through and use of urban space, rather than the more common conception of formal neighborhoods united by a homogeneity in population and landscape. Through this shift from formal to functional neighborhoods, we are able to not only provide a more contemporary view of Atlanta's neighborhood geographies, but also to provide a more relational understanding of these neighborhoods that emphasizes their connectivity and mutual constitution rather than their separation, isolation and distinctiveness.

\section{A. Data and Methodology}

This analysis follows a growing trend of using geotagged social media data as a proxy for people's aggregate daily mobility patterns over relatively long periods of time (cf. Noulas et al 2012; Liu et al 2014; Wu et al 2014; Huang and Wong 2016; Luo et al 2016; Wu et al 2016; Zhang et al 2016). While this data represents one of the most comprehensive and detailed ways of tracking such mobility patterns it is not without its shortcomings. The nature of social media data, as compared with data from mobile phone tracking or even an analog travel diary, is that it fails to record all movements by any given individual. Nonetheless, over longer periods of time, social media data can provide a reasonably accurate view of those key points of interest for individuals, even if it cannot provide 
detailed information of the means by which they moved between them. The second major shortcoming of social media data is that it represents a limited, non-representative and self-selected sample of the whole population of a given city. That said, the biases of the data do not invalidate its usefulness. Indeed, the most significant observed biases in Twitter data are in age and geography, with both younger people and more urban areas being overrepresented (Mislove et al 2011; Pew Research Center 2018), though socioeconomic status and skill level have also been shown to be significant influences on the use of such sites (Hargittai 2018). But perhaps contrary to received wisdom, social media data from Twitter actually overrepresents the voices of black users relative to the general population in the United States (Hargittai and Litt 2011; Pew Research Center 2018). Indeed, as Murthy et al (2016) have found, historically black cities in the US are some of the most active centers of tweeting activity across the country. Elsewhere, Shelton et al (2015) have demonstrated that even when social media data is spatially uneven, this doesn't necessarily denote that places with fewer data points aren't adopting the technology, but rather that offline social inequalities have shaped the everyday routines of residents in those areas such that they are producing data, just in other parts of the city. In this way, leveraging this data to understand the aggregate mobilities and activity spaces of urban residents may actually provide a greater voice to some underrepresented groups in understanding urban processes than has historically been the case with top-down government-driven planning initiatives.

In this case, we use a dataset consisting of all geotagged tweets sent worldwide since 2012, as collected by the DOLLY Project at the University of Kentucky (Poorthuis and Zook 2017). We extract all messages sent from the greater Atlanta area ${ }^{1}$ within a three-year period from July 2012 to June 2015, yielding a total of 28.5 million tweets. We then further filter based on the boundaries of

\footnotetext{
${ }^{1}$ Defined as a bounding box with the following coordinates as left, bottom, right and top coordinates respectively: -
} 84.814968; 33.560851; 34.258351; and -84.181023. 
the City of Atlanta (see Figure 1) and only keep tweets where the location is derived from the more precise cell phone or GPS triangulation. As we are primarily interested in spatial interaction we further select only those users who have sent more than two messages during the study period. Our final dataset consists of 124,792 users who have tweeted a total of 8.2 million times from the greater Atlanta area.

We use this initial dataset as a proxy for each user's activity space. This particular use has become quite common with both mobile phone data (Ahas et al 2010) as well as social media data (Hristova et al 2016; Poorthuis 2018), as such datasets hold information on the links between a person and the various locations that person frequents. These locations are then connected through that person: if a person visits location $\mathrm{A}$ and subsequently also visits location $\mathrm{B}$, a link can be drawn between those two locations. The more often a person makes this trip, the stronger that link may be.

To construct this network of links between locations, we follow the approach outlined in more detail elsewhere by Poorthuis (2018), and so will only highlight a few relevant methodological points here. When dealing with social media data, we need to address that users tend to have different levels of activity and, if not taken into account, power users might dominate the resulting datasets. To do this, we weigh each user's activity space in the following way:

$$
W_{i j}=\sum_{u=1}^{U} \frac{T_{i u}+T_{j u}}{(L+1) \sum_{l=1}^{L} T_{l u}}
$$

The weight (W) of the link between two locations $i$ and $j$ is the sum of all users' $(u)$ connections between those locations (L). An individual user's 'contribution' to that connection is then determined by the sum of tweets $(T)$ in the two locations by that user, relative to the total weight of 
all tweets between all locations for the user'. This results in each user having exactly the same 'vote' in the resulting interaction network. To ease subsequent computations, we define a 'location' here as a grid cell of 0.0075 degrees (roughly 800 meters), yielding a total of 998 grid cells within the Atlanta area. Between those 998 locations, there are a total of 407,002 links ${ }^{3}$.

In order to turn this spatial interaction data into functional neighborhoods, we draw on both the longer histories of regionalization discussed above, as well as more recent advances in network analysis and community detection algorithms (cf. De Montis et al 2007; Gao et al 2013; Liu et al 2014). Many approaches in both regionalization and community detection share a drive to find an objective or 'best' fit for the neighborhoods that are yielded by such algorithms. For example, community detection algorithms often use the concept of modularity, a goodness-of-fit metric that relates to how well a network is partitioned (cf. Lanchichinetti and Fortunato 2010). This approach yields a single metric that can then be algorithmically optimized. However, its adoption within geography and regionalization also brings with it an ontological view on communities and neighborhoods as somehow 'natural' and 'objective', a view that is not necessarily compatible with our theoretical understanding of space as fuzzy and relational.

For this reason, while we build on the significant achievements of network analysis and community detection, we also diverge from it. Instead of over-generalizing and finding the set of optimal neighborhoods, we show here how different algorithmic parameters may yield different outcomes that can able help us understand the variegated and fuzzy nature of urban space. Specifically, we use the Infomap algorithm (Rosvall et al 2010) to find or 'detect' neighborhoods in the network of

\footnotetext{
${ }^{2}$ For a longer description of the weighting approach, we refer to Poorthuis (2018).

${ }^{3}$ Mean weight of all links $=0.30$; Standard deviation weight $=8.81$; Max weight $=2795.58$. It is worth noting here that a different grid size or shape could potentially produce different neighborhood outputs due to the persistent relevance of the Modifiable Areal Unit Problem.
} 
spatial interactions described previously. Particularly relevant in this regard is that the Infomap algorithm gives the researcher control over the outcome of the algorithm by exposing a scale or size parameter, which is referred to as Markov time (see Schaub et al 2012 for a more in-depth discussion). We use this parameter in our analysis in order to generate neighborhood boundaries at different scales, allowing us to then analyze the relative stability of different neighborhoods in the city as the scale parameter or Markov time changes.

Together, the combination of millions of geotagged tweets forming a record of many individuals' mobility patterns (including those of groups who might have traditionally been left out of such datasets), an understanding of space as fluid and relational and neighborhoods as defined not only formally but also functionally, and an approach to regionalization that doesn't seek to privilege a single 'best' output, work together to produce the speculative reimagining of Atlanta's neighborhoods provided below. While our analysis points to the problems with the way the NPU system's geography was developed and implemented, our own mappings the city's neighborhoods are not without their own shortcomings, or meant to supplant all other ways of thinking about and defining the city's neighborhoods. But our purpose here is to utilize this approach to privilege an alternative perspective on what constitutes a neighborhood and how we can (and should) draw its boundaries.

\section{B. Mapping Stability and Change in Neighborhood Boundaries}

Before we examine the relational neighborhood geographies based on our analysis of geotagged Twitter data, it is worth stressing that the fluidity and fuzziness of neighborhood boundaries is inherent to the concept of a neighborhood, regardless of the particular data being used. Although the boundaries of Atlanta's NPUs have seen scarcely any change since their original creation, the 
boundaries of Atlanta's neighborhoods are anything but natural and unchanging. By using a series of archival maps available through Georgia State University's Planning Atlanta digital collection, we can understand how the City of Atlanta partitioned its neighborhoods in different ways in the lead-up to their more-or-less permanent enshrinement as part of the NPU system.

Figure 2 below draws specifically on a series of four archival maps from the Planning Atlanta collection that were digitized and then traced for further analysis, as seen in Figure 2A-D . Figures 2A-D show a significant evolution in the number, size and shape (not to mention names, which are not depicted) over a relatively short period of time from 1963-1975, with plenty of change occurring in just the three maps created between 1973-1975. Perhaps most evident from these four maps is the significant fragmentation of the city's neighborhood spaces, with Figures 2A and 2C in particular demonstrating that not every place within the city was assigned as being part of a given neighborhood. Figure 2E visualizes these four different maps overlaid on top of one another, with darker line weights highlighting those borders that are shared across different definitions. Ultimately, this map highlights that in spite of attempts to use these sub-urban neighborhood definitions as means of making the city more legible, when taken in the aggregate, they highlight the fundamental complexity and subjectivity of urban space that defies the belief that such partitions of space lead to a more precise understanding of urban processes.

\footnotetext{
4 These maps are as follows:

Staging Areas (1963) http://digitalcollections.library.gsu.edu/cdm/singleitem/collection/atlmaps/id/1828/rec/1 Neighborhood Data Collection Areas (1973)

http://digitalcollections.library.gsu.edu/cdm/singleitem/collection/atlmaps/id/1766/rec/2

Neighborhoods (1973) http://digitalcollections.library.gsu.edu/cdm/singleitem/collection/atlmaps/id/2448/rec/15

Planning Units (1975) http://digitalcollections.library.gsu.edu/cdm/singleitem/collection/atlmaps/id/1720/rec/68
} 


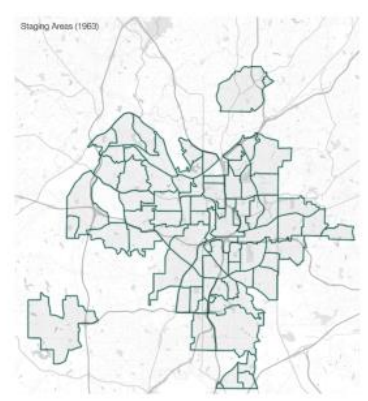

(a)

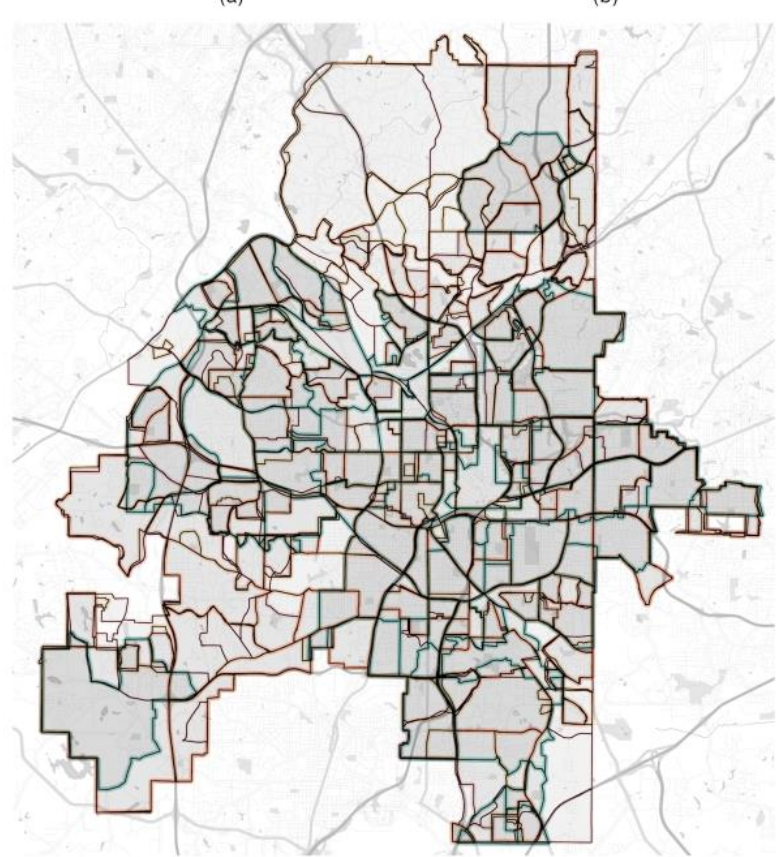

(e)

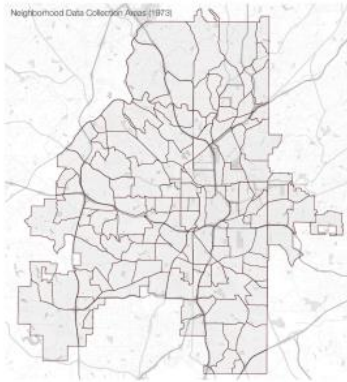

(b)

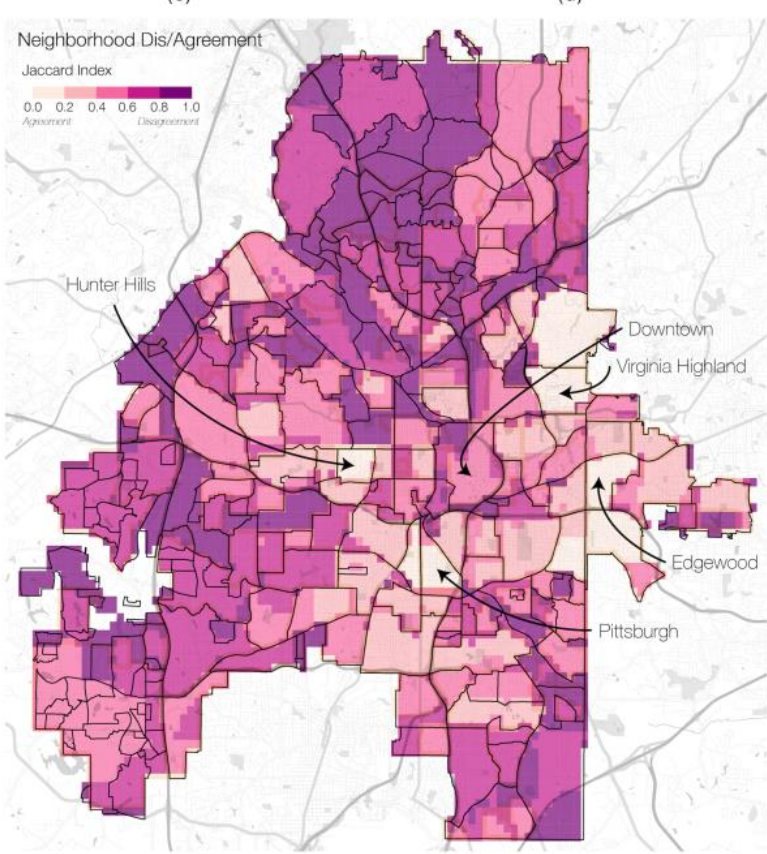

(f)

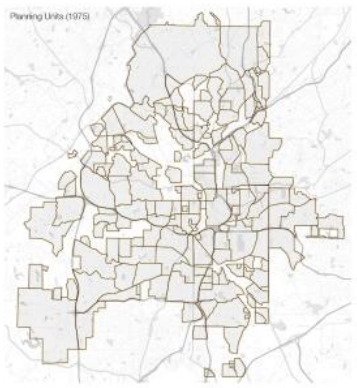

(d)

Figure 2: Dis/Agreement in Historical Neighborhood Geographies over Time. Figures (a)-(d) show four different sets of historic neighborhoods from 1963, 1973, 1973 and 1975, respectively. To highlight discrepancies between these different neighborhoods, Figure (e) overlays the four different sets on top of each other. Figure (f) utilizes the Jaccard Index to quantitatively summarize the (dis)agreement between sets for different locations.

In order to compare the similarities and differences across these four maps beyond the simple visual analysis enabled by overlaying each set of polygons (as we do in Figure 2E), we employ the Jaccard Index, or Jaccard Similarity Coefficient (Jaccard 1912). The Jaccard Index can be used to compare the similarity of two sets (in this case two sets of neighborhoods) and yields a range from 0 (similar) to 1 (not similar). In practical terms, we first divide up Atlanta into a set of grid cells. For each grid cell, we determine its relation to all other grid cells: if both cells are located in the same neighborhood we assign a 1 , if not we assign a 0 . This creates a binary 'shared neighborhood' vector 
for each location, that we can subsequently compare across the five different neighborhood sets. As the Jaccard index is designed to compare only two vectors at the same time, this results in 10 possible comparisons and thus Jaccard coefficients for each location. We take the mean across coefficients to visually represent the degree of overlap, as seen in Figure 2F. In addition to the Jaccard Index, Figure 2F also shows the present-day definition of the city's 244 neighborhoods for comparisons of how coherent they are over time.

Figure $2 \mathrm{~F}$ demonstrates that only a handful of neighborhoods are consistently defined across each of the different historic maps analyzed here. They include everything from historically black and middle-class, but since declining, neighborhoods like Hunter Hills on the city's Westside, to working-class neighborhoods like Pittsburgh and Adair Park just to the south of downtown, as well as from more white and affluent neighborhoods on the city's eastside like Virginia-Highland and Morningside-Lenox Park, to neighborhoods that have undergone multiple shifts in their demographic and socio-economic composition like Ormewood Park, East Atlanta and Edgewood.

In some cases, these consistently defined neighborhoods are the result of tangible, material boundaries that clearly separate one area from another. For instance, both Pittsburgh and Adair Park are bounded by highways and railroad tracks that provide clear, relatively unchanging borders. But in other places, these boundaries are more a function of history and social division. Edgewood presents an interesting case because it has both material and immaterial borders. Three sides of the Edgewood neighborhood accord with major thoroughfares. But this isn't the case for the neighborhood's eastern boundary with the Kirkwood neighborhood. This hardened, consistent boundary can be attributed in part to the social divisions between these two areas: Edgewood has long been home to more black residents than many of the surrounding neighborhoods. Indeed, part 
of the border between Edgewood and Kirkwood is defined by the edge of the increasingly infamous Edgewood Court apartment complex (Raviv 2016). This border is highlighted in an episode of the Vice TV program Noisey Atlanta ${ }^{5}$, which juxtaposes the poverty of Edgewood Court with the luxury condos being built just yards away on the other side of the boundary with Kirkwood. It is through these kinds juxtapositions that one can understand how the seemingly stable borders visualized in our mapping are made material not just in (relatively) unpassable barriers like a freeway, but also in the ways that racial and class biases are instantiated in urban landscapes and neighborhood definitions.

\section{Mapping Relational Neighborhood Geographies with Geotagged Tweets}

Using geotagged social media data as a proxy for people's urban mobilities provides an important window into how these invisible barriers are made manifest in people's everyday routines. Figure 3 shows a variety of outputs from the Infomap algorithm at different spatial scales, as discussed above. Figures 3A-D highlight how the output of the Infomap algorithm changes considerably depending on the scale or Markov time parameter, showing outputs at Markov times $0.80,0.83,0.88$ and $0.90 .{ }^{6}$ For instance, going through each of the Markov times represented in Figure 3, one goes from a total of just 20 Twitter neighborhoods in Figure 3D to 26, 54 and 108 neighborhoods, respectively. Of particular interest is Figure 3C, which is the output at Markov time 0.88, producing a total of 26 neighborhoods. This output most closely approximates the city's 25 NPUs and is thus most directly suggestive of what an alternative set of boundaries for the city's NPUs would be based on functional connections, were one to hold other aspects of the system constant.

\footnotetext{
${ }^{5}$ Available from https://youtu.be/psMrUGRSQbI

${ }^{6}$ While the output at Markov time 0.88 is shown because it most closely approximates the number of NPUs in Atlanta, the other Markov times shown are selected more-or-less randomly simply in order to show the wide variation in outputs even with only small changes in the scale parameter.
} 

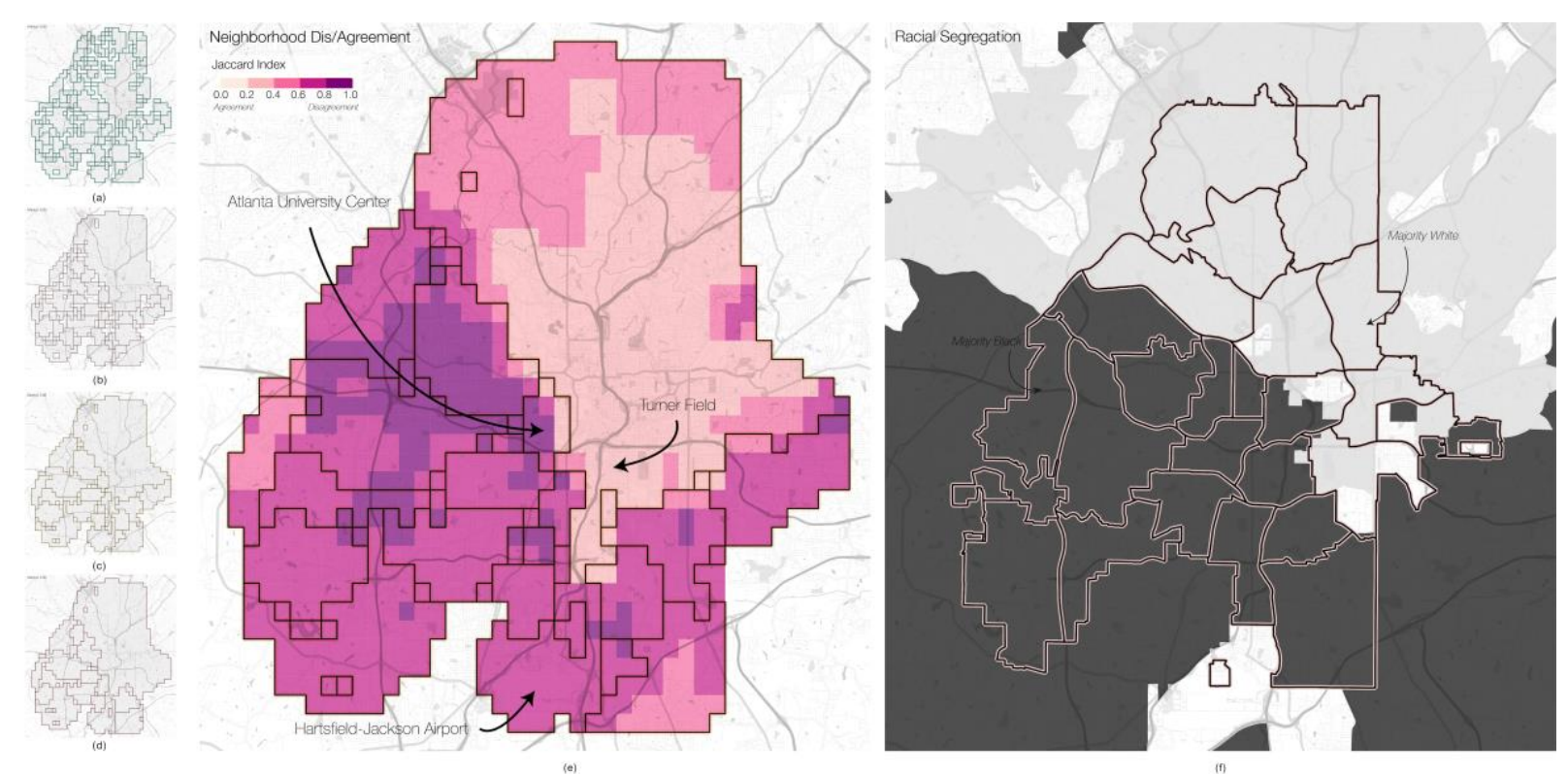

Figure 3: Changing Neighborhood Geographies According to Twitter. Figures (a)-(d) bighlight different outputs of the Infomap clustering algorithm with different scale (Markov time) parameters, showing outputs at Markov times $0.80,0.83,0.88$ and 0.90 , respectively. Areas with no color fill indicate isolates with not enough connections to other cells to form a larger neighborhood (i.e. isolates). Figure (e) shows the (dis)agreement between those scales by utilizing the Jaccard Index. To contextualize these neighborhoods, Figure (f) shows the census tracts that have a majority of either white or black residents.

These maps also interesting because of the particularities of how the geographies of these functional, relational neighborhoods can change drastically with only small adjustments to the scale parameter. For instance, the area at the intersection of NPUs A, C and D in northwest Atlanta is fairly stable from Markov time 0.83-0.90 (Figures 3B-D) but becomes significantly fragmented when the scale parameter is lowered to 0.80 (Figure 3A). Conversely, The Atlanta University Center (AUC) just west of downtown, home to the city's historic black colleges of Morehouse, Spelman and Clark Atlanta, is lumped in with the larger northeast cluster at Markov time 0.90. But adjusting the scale parameter downward, the AUC quickly breaks off and forms its own neighborhood, highlighting at once the coherence of the area and its connections with the rest of the city through the movements of its student population. 
The stability of these relational Twitter neighborhoods across spatial scales is summarized in Figure 3E, which again utilizes the Jaccard Index to demonstrate dis/agreement between scales. Arguably the most important aspect of these maps is the size and stability of the one large neighborhood that covers the majority of Atlanta's northeast area. This area is notable primarily because it approximates the racial geography of the city, where predominantly white and more affluent residents live to the north and east, with predominantly black and poorer residents to the south and west, as can be seen in Figure 3F. In other words, our more functional and relational understanding of Atlanta's neighborhoods highlights that in spite of the bevy of different official neighborhoods throughout the city's northern and eastern reaches, the city's white residents tend to have one fairly coherent activity space that reaches across the entirety of these areas. This one large neighborhood deviates so much from the conventional definition of the city's neighborhood boundaries that it includes all of six NPUs, the majority of another five, and at least part of six more. Of the city's 244 officially-recognized neighborhoods, our northeast neighborhood includes all of 85 and parts of an additional 40. Therefore, we can say that from a functional perspective, many of these distinctions are fairly meaningless, as residents are much more expansive in their everyday mobilities through the city, albeit still largely confined to majority white spaces.

The highly racialized nature of these resulting neighborhood maps should come as no surprise for anyone familiar with Atlanta, one of the country's most segregated and unequal cities. But a number of eccentricities in the resulting map complicate this picture in small ways. For instance, while the northeast neighborhood largely mirrors the city's racial divide, it also reaches beyond these stereotypically white spaces. Consistently across different Markov times, this neighborhood stretches all the way south towards the city's Hartsfield-Jackson Airport, also including parts of Atlanta's 'tourist bubble' (Newman 2002) like downtown and the Auburn Avenue historic district, home to 
the Martin Luther King, Jr. historic site, an area the city has actively tried to shape into a heritage tourist destination that caters to such white residents and visitors (Inwood 2010). It is also worth highlighting the area around Turner Field, just south of downtown and to the east of the downtown connector, which similarly remains a part of this northeast cluster even as the Markov time is lowered to 0.80 , despite being surrounded by a historically black neighborhood. But even this particularity is part of a bygone era, as the Braves relocated to the largely white and affluent Cobb County suburbs in 2017 in an effort to ostensibly better serve the social and spatial preferences of their fans (Walter 2015).

The stability of the northeast neighborhood is all the more interesting when cast against the relative instability of the neighborhoods in the western portion of the city, as demonstrated by the darker purple hues in Figure 3E. The contradictions between the coherence of the predominantly white northeast neighborhood and the divergence of the largely black cluster on the Westside calls attention to the racial compromise of the city's governing regime in the mid- $20^{\text {th }}$ century under Mayor William Hartsfield, where in an effort to move black residents further from the city center in order to open it up for redevelopment, land on the city's westside was offered to black residents for development, under the condition that blacks not attempt to move to Atlanta's wealthier and whiter northside (Stone 1989). Ultimately, this shows the incongruity between the ways that these spaces are imagined as more-or-less coherent by white residents the local state and the reality of their significant variegation in the everyday lived realities of residents. That is, these maps help to highlight the diversity, differences and segmentation across the city's predominantly black neighborhoods, with multiple alternative understandings of neighborhood spaces emerging from the movements of residents as captured in geotagged Twitter data. 


\section{Comparing Historical and Twitter Neighborhood Geographies}

In Figure 4 we compare the two neighborhood geographies more directly by overlaying the Jaccard Index map for historical neighborhood boundaries with the Twitter neighborhood boundaries. As with the findings from Figure 3, arguably the most interesting result of this map regards the northeast neighborhood identified previously. While Figure 3E showed this neighborhood to be extremely stable across multiple Markov times in our analysis of Twitter data, comparing it with the administrative definitions tells a more complex story. Though this northeast neighborhood cluster is something of a proxy for the activity space of Atlanta's white population, a considerable portion of the space within this neighborhood cluster has some of the lowest rates of cohesion amongst our different historical neighborhood boundaries. So even though the official names and boundaries of these areas have changed consistently over time, our analysis of functional neighborhoods shows that these places are actually quite well integrated with one another in spite of such change.

At the same time, some of those areas where our historic neighborhood definitions are most cohesive and consistent over time don't match up neatly with the outputs from the regionalization algorithm. In some cases, they sit at the intersection of multiple functional neighborhoods, while in others they exist as just one small part of much larger functional neighborhoods that they're seen as separate and apart from in more conventional definitions. This is especially true for the area around NPU K on Atlanta's Westside. Within this one NPU sit side-by-side some of the city's most and least coherently defined neighborhoods based on our historical analysis. But when looking at our Twitter neighborhoods, what was previously lumped together as part of one NPU is now divided into part of five different Twitter neighborhoods. Even the Hunter Hills neighborhood (discussed previously in Figure 2), which is defined consistently and coherently across the historical maps, ends up being split into three different functional neighborhoods. 


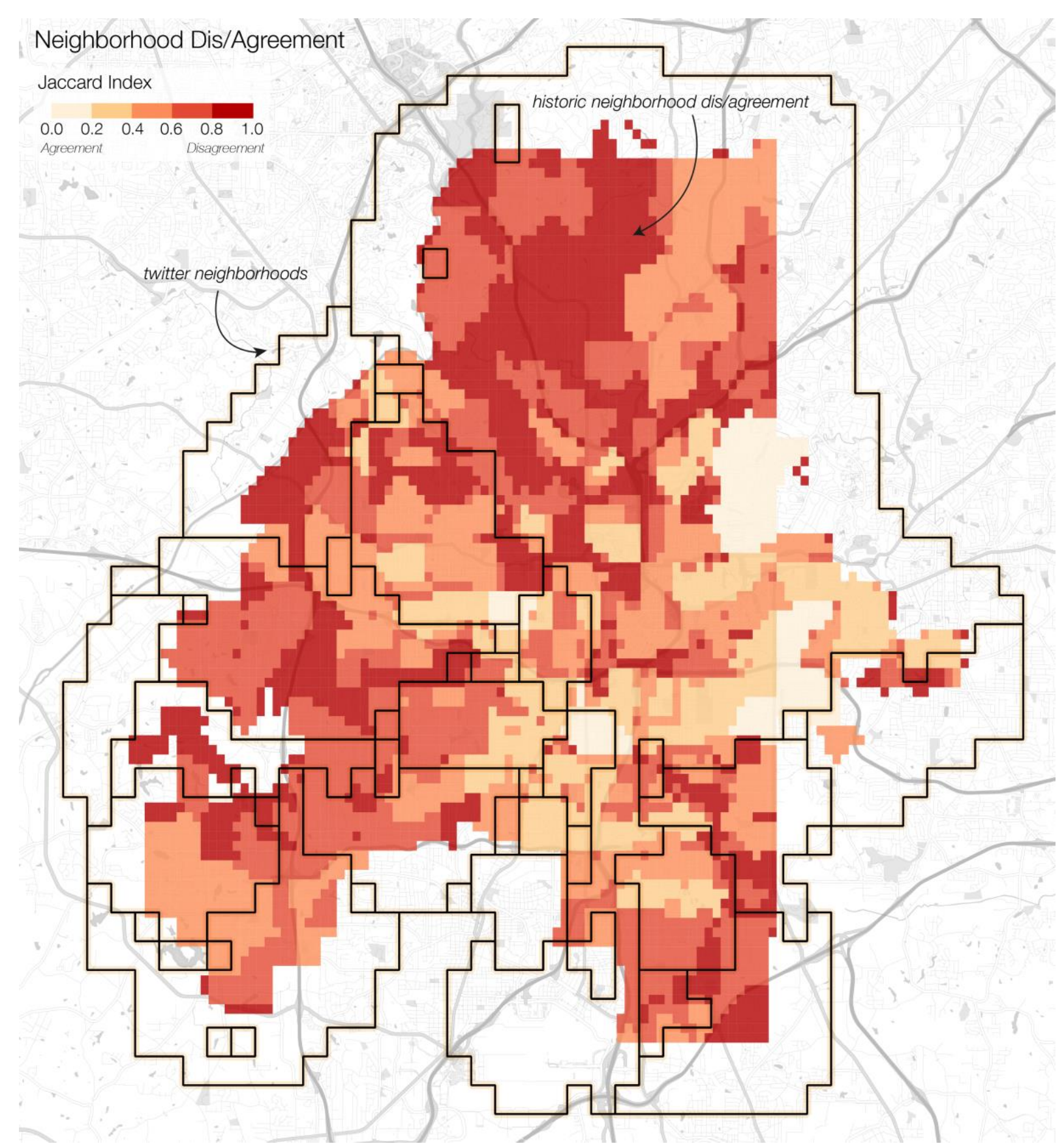

Figure 4: Comparison of the (dis)agreement index between different sets of historical neighborboods with the boundaries of Twitter neighborhoods.

We take a more abstract approach in Figure 5 by comparing the Jaccard Index for Twitter neighborhoods with the Jaccard Index for historical neighborhoods, specifically focusing on those places with Jaccard Index scores greater than 0.50 for either set of neighborhoods. Though most of the city is characterized by some degree of instability in either historic or Twitter neighborhoods (or 
both), a number of places demonstrate a significant degree of coherence and stability across both neighborhood types (as denoted by those areas without the hatched pattern). This includes areas ranging from a variety of neighborhoods on the city's eastside, as well as some central Atlanta neighborhoods south of I-20.

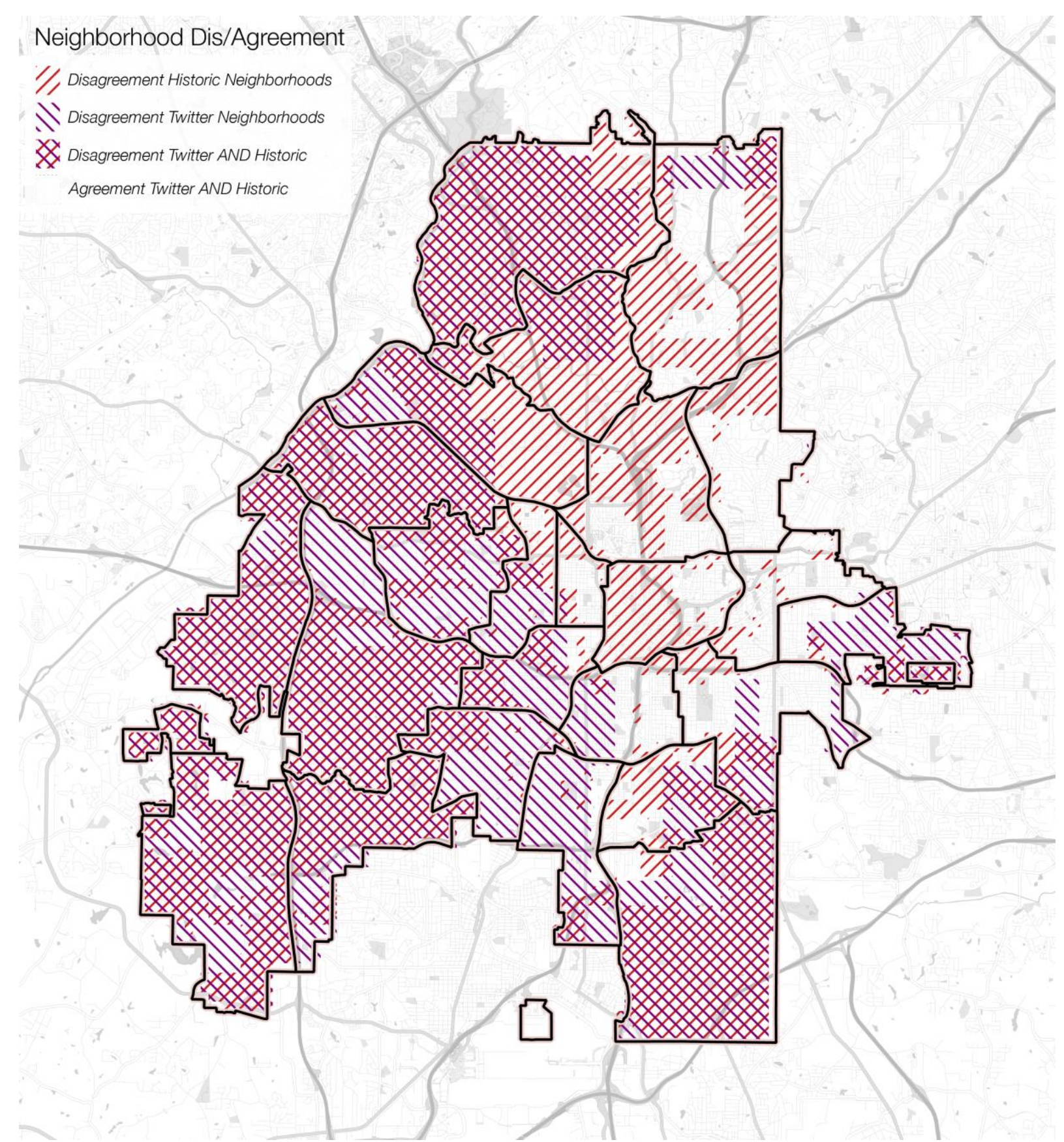

Figure 5: Comparison of the (dis) agreement index between historical and Twitter neighborhoods. Areas with Jaccard Index scores greater than 0.50 (indicating significant disagreement) are filled with a hatched pattern. 
One of the more striking insights from this analysis is that within this significant area of the city characterized by substantial change in neighborhood identification across both our historic and Twitter neighborhoods (as symbolized by the cross-hatched areas) is the neighborhood surrounding the intersection of Peyton Road and Harlan Road on the city's Westside, just inside the Perimeter and south of I-20. This area was the site of 'Atlanta's Berlin Wall', a pair of physical barriers set up by Mayor Ivan Allen Jr. in 1962 as a means of physically limiting the spatial mobility of black Atlantans into a predominantly white neighborhood, while also symbolically attempting to limit their social mobility through a material statement in support of the maintenance of racial residential segregation (Crater 2011; see also Kruse 2005). While this area quickly became a prototypical example of blockbusting and white flight upon the removal of the barriers, the surrounding area of Cascade Heights would continue on to be one of the most prominent neighborhoods for Atlanta's black elite well into the present day. But in our analysis, this area is visualized as a place of significant change, both in historic maps as the racial contours of the city were being remade, as well as in the present day, where the variegated spatial mobilities of Atlanta residents work to construct and reconstruct neighborhoods at multiple scales on an everyday basis.

\section{Conclusion}

Far from the Westphalian neighborhood imaginary of "the city as fully divided among different neighborhoods pictured as non-overlapping and of clear outline” (Madden 2014: 473), this paper has highlighted that the nature of neighborhoods is, and has long been, one of relationality and multiplicity. Through an analysis of both historical neighborhood definitions and contemporary urban dynamics, this paper has documented the evolution of neighborhoods as they are imagined and lived by both powerful and average Atlantans. Rather than the Westphalian and fundamentally static vision of neighborhoods promoted by the city's NPU system, our analysis has shown that 
neighborhoods have long been contested and recreated within Atlanta. On the one hand, the redefinition of neighborhood names and boundaries in official city plans and documents leading up to the NPU system shows that neighborhoods are not unchanging, external forces on social life, but rather a reflection of larger social and spatial reconfigurations. On the other hand, our analysis of contemporary neighborhoods through the lens of everyday mobilities shows that the unchanging geography of the NPU system doesn't reflect the actual activity spaces and routines of the city's residents. This fundamental relationality of urban neighborhoods ultimately contradicts the logics of the NPU system, with our redrawing of the city's neighborhoods based on geotagged social media presenting an alternative vision of where these boundaries might lie, albeit in a fundamentally fuzzy and nondeterminate way.

As such, this paper calls into question the reification of neighborhood boundaries, whether in the form of planning units or in the statistical geographies of the Census tract that often comes to stand in for a more qualitative and subjective understanding of neighborhood produced by those who actually inhabit such spaces. But this problem is, again, fundamental to the nature of neighborhoods. Any given definition of neighborhood boundaries is sure to be contradictory in some fashion or another. If, through political or practical necessity, neighborhoods need to be drawn - as is the case in Atlanta - it is thus important to also create mechanism to re-evaluate and interrogate the neighborhood boundaries on a regular basis. So while it is extremely difficult, if not impossible, to 'solve' this hurdle, our analysis has sought to demonstrate how a more critical analysis of how neighborhoods have come to be and changed over time can provide a useful antidote to the more rigid, instrumentalist understanding of neighborhoods often used elsewhere in geography and urban planning. 
At the same time, however, this work provides new insight into how these neighborhood geographies and the geographies of segregation in the city overlap and diverge. For instance, our analysis of relational Twitter neighborhoods demonstrated that the nature and evolution of the city's segregated landscape has meant the formation of a relatively coherent, but extremely large, space of white sociality covering the vast majority of the city's north and east, while predominantly black social spaces elsewhere are much more internally differentiated and variegated in the way that different people occupy, use and move through them. While it would be difficult, if not impossible, to infer causality for the spatial patterns demonstrated by our mappings, the fact that these maps highlight spaces of conflict and change, which quite often overlap considerably with historic flashpoints in broader urban political struggles, demonstrates the potentials for this kind of analysis to be connected to further work that investigates such conflicts, whether in places like the intersection of Peyton and Harlan Roads or Turner Field as we've discussed earlier in the paper, or in places like Buckhead's East Village and the Old Fourth Ward that have been the site of more recent tensions over racialized and classed codings of urban space (cf. Hankins et al 2012; Powers 2017). And though we have not explicitly explored such issues in this paper, these speculative redefinitions of the city's neighborhoods raise further questions for how the NPU system structures citizen participation into the planning process. In short, the question of who should have a say in decisions made in and about a certain area of the city is troubled by our analysis, which shows that neither proximity nor property ownership - the two means by which one is provided with a vote in NPU decision making processes - defines the totality of one's relationships and affinities with a given neighborhood.

Finally, beyond the specifics of investigating the definition and construction of neighborhoods, this paper has sought to contribute to broader methodological and theoretical debates within geography 
by demonstrating the utility of big data, mapping and quantitative analysis for understanding and uncovering these underlying relational geographies. While GIScience has long been associated with a Cartesian understanding of space, there remains a significant undercurrent of relational spatial theory within quantitative geography that has often been overlooked within conventional stories about the discipline's history and evolution. The seeming opposition of quantitative geography and relational space is, however, a contingent phenomenon, and one that this work has sought to chip away at, providing further possibilities for mobilizing these methods to develop alternative conceptualizations of social and spatial processes.

\section{References}

Ahas, Rein, Siiri Silm, Olle Järv, Erki Saluveer, and Margus Tiru. 2010. "Using Mobile Positioning Data to Model Locations Meaningful to Users of Mobile Phones." Journal of Urban Technology 17 (1): 3-27.

Anderson, Robert. 1985. "Many leaders in NPU see decline in effectiveness of the system". The Atlanta Journal and Constitution. 20 June. p. D1, D4.

Arribas-Bel, Daniel. 2015. “The Spoken Postcodes.” Regional Studies, Regional Science 2 (1): 458-61.

Berry, Brian J L. 1961. “A Method for Deriving Multi-Factor Uniform Regions.” Przeglad Geograficzny $33(2)$.

Berry, Brian J. L. 1971. "Introduction: The Logic and Limitations of Comparative Factorial Ecology.” Economic Geography 47 (2): 209-219.

Berry, Brian J. L., and John D. Kasarda. 1977. Contemporary Urban Ecology. Macmillan.

Bettencourt, Luis, and Geoffrey West. 2010. “A Unified Theory of Urban Living.” Nature 467 (7318): 912-913.

Bunge, William. 1966. Theoretical Geography. Royal University of Lund, Department of Geography.

Burgess, Ernest. 1923. “The Growth of the City: An Introduction to a Research Project.” Publications of the American Sociological Society 18 (1): 85-97.

Campbell, Colin. 1996. "Chief planner's legacy lies in neighborhoods". The Atlanta Journal and Constitution. 4 April. p. B1. 
Campbell, Elizabeth, Julia R. Henly, Delbert S. Elliott, and Katherine Irwin. 2009. "Subjective Constructions of Neighborhood Boundaries: Lessons from a Qualitative Study of Four Neighborhoods." Journal of Urban Affairs 31 (4): 461-490.

Chisholm, Matt, and Ross Cohen. n.d. "The Neighborhood Project". Available from: https://hood.theory.org/

City of Atlanta. n.d. "Neighborhood Planning Unit (NPU)". Available from: http:/ / www.atlantaga.gov/index.aspx?page $=739$

City of Atlanta. 1967. Social Report on Neighborhood Analysis.

City of Atlanta. 1973. The Value of Neighborhood Planning.

City of Atlanta. 1974. How to Do Neighborhood Planning.

Cordell, Actor. 1992. "42 more neighborhoods recorded in city since map of 181 in 1974”. The Atlanta Journal and Constitution. 9 April. p. E3.

Coulton, Claudia J., Jill Korbin, Tsui Chan, and Marilyn Su. 2001. “Mapping Residents’ Perceptions of Neighborhood Boundaries: A Methodological Note.” American Journal of Community Psychology 29 (2): 371-383.

Crampton, Jeremy W. 2006. "The Cartographic Calculation of Space: Race Mapping and the Balkans at the Paris Peace Conference of 1919." Social and Cultural Geography 7 (5): 731-752.

Cranshaw, Justin, Raz Schwartz, Jason I. Hong, and Norman Sadeh. 2012. "The Livehoods Project: Utilizing Social Media to Understand the Dynamics of a City." Proceedings of the Sixth International AAAI Conference on Weblogs and Social Media, 58-65.

Crater, Paul. 2011. “Atlanta's 'Berlin Wall'. Atlanta Magazine. 1 December. Available from: http://www.atlantamagazine.com/civilrights/atlantas-berlin-wall/

De Montis, Andrea, Marc Barthelemy, Alessandro Chessa, and Alessandro Vespignani. 2007. "The Structure of Interurban Traffic: A Weighted Network Analysis.” Environment and Planning B Abstract 34 (5): 905-924.

Eplan, Leon S. 2014. “The Genesis of Citizen Participation in Atlanta”. In Planning Atlanta, Harley Etienne and Barbara Faga, eds. American Planning Association. pp. 94-102.

Flowerdew, Robin, David J. Manley, and Clive E. Sabel. 2008. "Neighbourhood Effects on Health: Does It Matter Where You Draw the Boundaries?” Social Science \& Medicine 66 (6): 12411255.

Foskett, Ken. 1992. "Letter to the editor: Neighborhood planning units foster democracy". The Atlanta Journal and Constitution. 6 April. p. A8.

Gale, Stephen. 1976. "A Resolution of the Regionalization Problem and Its Implications for Political Geography and Social Justice." Geografiska Annaler. Series B, Human Geography 58 (1): 1-16. 
Galster, George. 2001. “On the Nature of Neighbourhood.” Urban Studies 38 (12): 2111-2124.

Gao, Song, Yu Liu, Yaoli Wang, and Xiujun Ma. 2013. "Discovering Spatial Interaction Communities from Mobile Phone Data.” Transactions in GIS 17 (3): 463-481.

Garrison, William L., and Duane F. Marble. 1964. "Factor-Analytic Study of the Connectivity of a Transportation Network." Papers in Regional Science 12 (1): 231-238.

Goddard, J. B. 1970. "Functional Regions within the City Centre: A Study by Factor Analysis of Taxi Flows in Central London." Transactions of the Institute of British Geographers 49: 161-182.

Grigg, David. 1965. "The Logic of Regional Systems." Annals of the Association of American Geographers 55 (3): 465-491.

Hankins, Katherine B., Robert Cochran, and Kate Driscoll Derickson. 2012. "Making Space, Making Race: Reconstituting White Privilege in Buckhead, Atlanta.” Social \& Cultural Geography 13 (4): 379-397.

Hargittai, Eszter, and Eden Litt. 2011. "The tweet smell of celebrity success: Explaining variation in Twitter adoption among a diverse group of young adults." New Media \& Society 13 (5): 824842.

Hargittai, Eszter. 2018. "Potential Biases in Big Data: Omitted Voices on Social Media." Social Science Computer Review, forthcoming.

Harvey, David. 1969. Explanation in Geography. Edward Arnold.

Hemmens, George C. 1966. An analysis of urban travel and the spatial structure of urban activities. $\mathrm{PhD}$ Dissertation. Massachusetts Institute of Technology, Department of City and Regional Planning.

Hiskey, Michelle. 1991. "City's communities making the map". The Atlanta Journal and Constitution. 16 December. p. B1.

Hristova, Desislava, Anastasios Noulas, Chloë Brown, Mirco Musolesi, and Cecilia Mascolo. 2016. "A Multilayer Approach to Multiplexity and Link Prediction in Online Geo-Social Networks.” EPJ Data Science 5 (1): 24.

Huang, Qunying, and David W. S. Wong. 2016. "Activity Patterns, Socioeconomic Status and Urban Spatial Structure: What Can Social Media Data Tell Us?” International Journal of Geographical Information Science 30 (9): 1873-1898.

Hunter, Albert. 1979. "The Urban Neighborhood: Its Analytical and Social Contexts." Urban Affairs Review 14 (3): 267-288.

Inwood, Joshua F. J. 2010. "Sweet Auburn: Constructing Atlanta's Auburn Avenue as a Heritage Tourist Destination.” Urban Geography 31 (5): 573-594. 
Jaccard, Paul. 1912. "The Distribution of the Flora in the Alpine Zone." New Phytologist 11 (2): $37-$ 50.

Jones, Malia, and Anne R. Pebley. 2014. "Redefining Neighborhoods Using Common Destinations: Social Characteristics of Activity Spaces and Home Census Tracts Compared." Demography 51 (3): 727-752.

Kruse, Kevin M. 2005. White Flight: Atlanta and the Making of Modern Conservatism. Princeton University Press.

Kwan, Mei-Po. 2018. "The Limits of the Neighborhood Effect: Contextual Uncertainties in Geographic, Environmental Health, and Social Science Research." Annals of the American Association of Geographers, forthcoming.

Lancichinetti, Andrea, and Santo Fortunato. 2009. "Community Detection Algorithms: A Comparative Analysis.” Physical Review E 80 (5): 056117.

Lankford, Philip M. 1969. "Regionalization: Theory and Alternative Algorithms.” Geographical Analysis 1 (2): 196-212.

Linthicum, Tom. 1973. "Neighborhood Councils Proposed by Weltner". The Atlanta Constitution. 16 August. p. A22.

Liu, Yu, Zhengwei Sui, Chaogui Kang, and Yong Gao. 2014. "Uncovering Patterns of Inter-Urban Trip and Spatial Interaction from Social Media Check-In Data.” PLOS ONE 9 (1): e86026.

Luo, Feixiong, Guofeng Cao, Kevin Mulligan, and Xiang Li. 2016. "Explore Spatiotemporal and Demographic Characteristics of Human Mobility via Twitter: A Case Study of Chicago." Applied Geography 70: 11-25.

Madden, David J. 2014. "Neighborhood as Spatial Project: Making the Urban Order on the Downtown Brooklyn Waterfront.” International Journal of Urban and Regional Research 38 (2): $471-497$.

Martin, Lya and Steven A. Holmes. 1978. "City NPUs Face Intensive Examination”. The Atlanta Constitution. 9 June. p. C1.

Massey, Doreen. 1991. “A Global Sense of Place.” Marxism Today 35 (6): 24-29.

Merriner, Jim. 1975a. "District Planning Bid Hit". The Atlanta Constitution. 17 March. p. D8.

Merriner, Jim. 1975b. "Confusing Public Charged In City Planning Dispute". The Atlanta Constitution. 3 April. p. A5.

Mislove, Alan, Sune Lehmann, Yong-Yeol Ahn, Jukka-Pekka Onnela, and J. Niels Rosenquist. 2011. "Understanding the Demographics of Twitter Users." In Fifth International AAAI Conference on Weblogs and Social Media, 554-557. 
Murthy, Dhiraj, Alexander Gross, and Alexander Pensavalle. 2016. "Urban Social Media Demographics: An Exploration of Twitter Use in Major American Cities." Journal of Computer-Mediated Communication 21 (1): 33-49.

Newman, Harvey K. 2002. "Race and the Tourist Bubble in Downtown Atlanta." Urban Affairs Review 37 (3): 301-321.

Noulas, Anastasios, Salvatore Scellato, Renaud Lambiotte, Massimiliano Pontil, and Cecilia Mascolo. 2012. "A Tale of Many Cities: Universal Patterns in Human Urban Mobility." PLOS ONE 7 (5): e37027.

Nystuen, John D., and Michael F. Dacey. 1961. "A Graph Theory Interpretation of Nodal Regions." Papers of the Regional Science Association 7 (1): 29-42.

O'Sullivan, David, Luke Bergmann, and Jim E. Thatcher. 2018. "Spatiality, Maps, and Mathematics in Critical Human Geography: Toward a Repetition with Difference.” The Professional Geographer 70 (1): 129-139.

Park, Robert. 1915. "The City: Suggestions for the Investigation of Human Behavior in the City Environment." American Journal of Sociology 20 (5): 577-612.

Park, Robert. 1936. "Human Ecology.” American Journal of Sociology 42 (1): 1-15.

Parko, Joseph E. 1975. "Re-Discovery Of Community: Neighborhood Movement in Atlanta." Journal of the Community Development Society 6 (1): 46-50.

Pew Research Center. 2018. "Social Media Fact Sheet.” Pew Research Center, Internet and Technology Project. 5 February. Available from: http://www.pewinternet.org/fact-sheet/social-media/

Pierce, Joseph, Deborah G. Martin, and James T. Murphy. 2011. "Relational Place-Making: The Networked Politics of Place." Transactions of the Institute of British Geographers 36 (1): 54-70.

Poorthuis, Ate. 2018 “How to Draw a Neighborhood? The Potential of Big Data, Regionalization, and Community Detection for Understanding the Heterogeneous Nature of Urban Neighborhoods." Geographical Analysis 50 (2): 182-203.

Poorthuis, Ate, and Matthew Zook. 2017. "Making Big Data Small: Strategies to Expand Urban and Geographical Research Using Social Media.” Journal of Urban Technology 24 (4): 115-135.

Powers, Benjamin. 2017. "Putting the Brakes on Runaway Gentrification in Atlanta." CityLab, 10 November. Available from: https://www.citylab.com/equity/2017/11/putting-the-brakeson-runaway-gentrification-in-atlanta/545555/

Raviv, Shaun. 2016. “The High Price of Development”. Creative Loafing Atlanta. 7 July. Available from: http://clatl.com/atlanta/the-high-price-of-development/Content?oid=17398356

Rosvall, M., D. Axelsson, and C.T. Bergstrom. 2010. "The Map Equation.” The European Physical Journal Special Topics 178 (1): 13-23 
Russakoff, Dale. 1978. "City, Residents Face Off on Poor Process of NPUs”. The Atlanta Constitution. 11 June. p. A19.

Saporta, Maria. 1982. "Neighborhood planners will be cut to save funds". The Atlanta Constitution. 25 October. p. A10.

Schaefer, Fred K. 1953. "Exceptionalism in Geography: A Methodological Examination.” Annals of the Association of American Geographers 43 (3): 226-249.

Schaub, Michael T, Renaud Lambiotte, and Mauricio Barahona. 2012. "Encoding Dynamics for Multiscale Community Detection: Markov Time Sweeping for the Map Equation.” Physical Review E 86 (2): 026112.

Shelton, Taylor, Ate Poorthuis, and Matthew Zook. 2015. "Social Media and the City: Rethinking Urban Socio-Spatial Inequality Using User-Generated Geographic Information.” Landscape and Urban Planning 142: 198-211.

Sheppard, Eric. 1995. "GIS and Society: Towards a Research Agenda." Cartography and Geographic Information Systems 22 (1): 5-16.

Shevky, Eshref, and Wendell Bell. 1955. Social Area Analysis. Stanford University Press.

Soja, Edward W. 1980. "The Socio-Spatial Dialectic." Annals of the Association of American Geographers 70 (2): 207-225.

Sperling, Jonathan. 2012. "The Tyranny of Census Geography: Small-Area Data and Neighborhood Statistics.” Cityscape 14 (2): 219-223.

Stone, Clarence Nathan. 1989. Regime Politics: Governing Atlanta, 1946-1988. University Press of Kansas.

Taylor, Ralph B. 2012. "Defining Neighborhoods in Space and Time.” Cityscape 14 (2): 225-230.

Walter, Andy. 2015. "Mapping Braves Country”. Atlanta Studies. 2 November. Available from: https://www.atlantastudies.org/mapping-braves-country/

Wheatley, Thomas and Robert Isaf. 2015. "Wither the NPU?”. Creative Loafing Atlanta. 26 March. Available from: http://www.clatl.com/news/article/13082298/wither-the-npu

Woodruff, Andy. 2013. "Neighborhoods as seen by the people". Bostonography. 27 June. Available from: http://bostonography.com/2013/neighborhoods-as-seen-by-the-people/

Wu, Lun, Ye Zhi, Zhengwei Sui, and Yu Liu. 2014. "Intra-Urban Human Mobility and Activity Transition: Evidence from Social Media Check-In Data.” PLOS ONE 9 (5): e97010.

Wu, Wenjie, Jianghao Wang, and Tianshi Dai. 2016. "The Geography of Cultural Ties and Human Mobility: Big Data in Urban Contexts." Annals of the American Association of Geographers 106 (3): 612-630. 
Zhang, Weiyang, Ben Derudder, Jianghao Wang, Wei Shen, and Frank Witlox. 2016. "Using Location-Based Social Media to Chart the Patterns of People Moving between Cities: The Case of Weibo-Users in the Yangtze River Delta." Journal of Urban Technology 23 (3): 91-111.

Zorbaugh, Harvey. 1926. "The Natural Areas of the City." Publications of the American Sociological Society 20 (1): 188-197. 